\title{
Detecting Defects in Photovoltaic Panels with the Help of Synchronized Thermography
}

\author{
Christian Schuss, Member, IEEE, Kari Remes, Kimmo Leppänen, Juha Saarela, Tapio Fabritius, \\ Bernd Eichberger, and Timo Rahkonen, Member, IEEE
}

\begin{abstract}
This paper investigates defects in photovoltaic (PV) panels, more precisely, the location of defects in PV panels. With the help of electrical verification, it is possible to verify the impact of defects on output performances. However, it is not possible to determine the location of defects in order to address the origin of problems, for example, in the manufacturing process of PV panels. In this paper, the focus lies on finding similarities in the location of defect areas in PV panels. Samples were characterised with the help of synchronized thermography (ST) and time-resolved thermography (TRT) in order to obtain infrared (IR) images of PV panels. IR-images are helpful to obtain a visual image on the health of PV panels, identify the position of defects and estimate the influence of defects on the output power. This information can be useful, for example, for improving the fabrication process of $\mathrm{PV}$ panels.
\end{abstract}

Index Terms-defect, interconnection, photovoltaic cell, photovoltaic panel, solar energy, synchronized thermography, timeresolved thermography.

\section{INTRODUCTION}

$\mathbf{C}$ OMMONLY, photovoltaic (PV) panels are verified by electrical measurements in order to obtain the characteristic $I-V$ (Current-Voltage) curve [1]-[3]. The slope of the $I-V$ curve provides information on the output performance of the PV panel in terms of available output current and power at different operating voltages [4], [5]. Moreover, with the help of electrical measurements, parameters can be verified which are needed for PV simulation models [1]-[3], [6]-[8].

Previous research has shown that differences in output power of PV panels sometimes exceeded the tolerance limits specified by PV manufacturers [3]. Some PV panels exhibited significantly less power than other PV panels. However, it was not possible to clearly determine the origin of the observed deviation in output power [3], since there were no signs of weak connections or breakages in PV cells which could help to explain the differences in output power levels.

A major disadvantage of the electrical verification of PV panels is that precise illumination and temperature are required

This work was financially supported by Infotech Oulu and the Faculty of Information Technology and Electrical Engineering (ITEE) of the University of Oulu.

C. Schuss, and T. Rahkonen are with the Circuits and Systems (CAS) Research Unit, University of Oulu, 90014 Oulu, Finland (e-mail: christian.schuss@oulu.fi).

K. Remes, J. Saarela, and T. Fabritius are with the Optoelectronics and Measurement Techniques (OPEM) Research Unit, University of Oulu, 90014 Oulu, Finland.

K. Leppänen is with Mettler-Toledo $\mathrm{GmbH}, 8603$ Schwerzenbach, Switzerland.

B. Eichberger is with the Institute of Electronic Sensor Systems, Graz University of Technology, 8010 Graz, Austria.

Accepted Version February 15, 2018 in order to obtain comparable measurement results. Moreover, electrical measurements do not provide information on the location of defects in PV panels. Thus, PV panels were characterized with the help of synchronized thermography (ST) to obtain a better understanding of the cause for the deviation in output power on one hand, and to obtain a visual image of the health of the PV panel and the location of defects on the other [9]-[11].

In [12], an infrared (IR) camera was used which offered a higher resolution than the IR-camera used in previous research [9]. In this way, we were able to localize defects in PV panels more precisely. In addition, a portable IR-camera was used, which can be attached to a smartphone, for example, an iPhone or an Android smartphone. With the help of a portable IRcamera, ST becomes a portable measurement tool and can be used, for example, by consumers to analyze their PV panels.

In this paper, we present an improved measurement setup which offers several advantages and benefits over the measurement setup used in [12] and in other previous research [9]-[11]. The focus lies on time-resolved thermography (TRT) which monitors continuously the heating process of PV panels. Instead of taking an IR-image after a certain time as in [9][12], IR-images are recorded at 30 frames per second. As a result, we are able to analyze temperature differences, which is useful in determining the loss of output power of PV panels with greater accuracy and in reducing the measurement time.

The structure of this paper is as follows: Section II discusses the configuration of a PV panel and presents the background of ST. In Section III, we show how the location of defects can be detected with the help of ST and how the resolution of the IRcamera influences the estimation of the loss in output power of the PV panel. In Section IV, we present the measurement setup of TRT and the experimental results of the heating process of PV panels are shown. We present conclusions in Section V.

\section{BACKGROUND AND RELATED WORK}

\section{A. Behaviour of Photovoltaics}

In PV simulation models, each PV cell in a panel is considered to be equal to the others. Commonly, commercial PV panels are made out of a large series connection of PV cells in order to achieve high voltage levels [13]-[15]. If one of the PV cells in the panel is defect, the PV panel performance can be significantly decreased. In a series connection of PV cells, the short-circuit current $\left(I_{s c}\right)$ depends on the short-circuit 
current of the weakest PV cell of the interconnection $\left(I_{s c, \min }\right)$ [9]-[11], as obtained by the following equation:

$$
\begin{array}{r}
P_{\text {ideal }}=V_{o c} \cdot I_{s c, \text { min }} \\
I_{s c, \text { min }}<I_{s c}
\end{array}
$$

where $P_{\text {ideal }}$ is the ideal power of the PV panel and $V_{o c}$ is the open-circuit voltage of the PV panel.

\section{B. Configuration of a PV panel}

Fig. 1 shows the interconnection of PV cells in a typical commercial PV panel. The example is taken from a PV panel which contains $36 \mathrm{PV}$ cells and produces an output power of 80 W. As seen in Fig. 1, all PV cells are connected in series with each other. In each row, there are 9 PV cells. Each string of PV cells is then connected to the next string of PV cells in the next row. The corner points are connected to a voltage terminal on which the output power can be obtained.

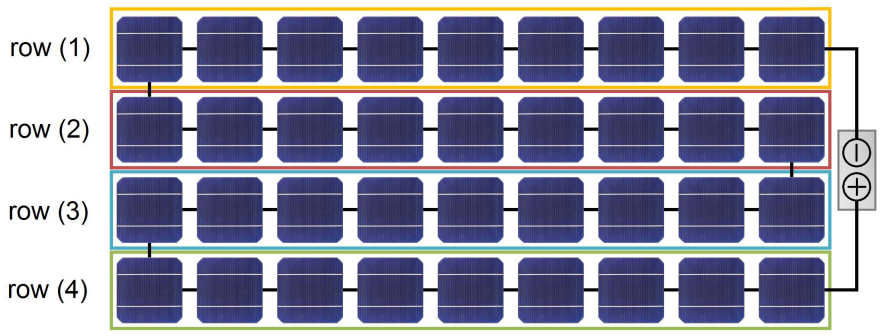

Fig. 1: Series connection of PV cells in a PV panel

In PV models, the behaviour of a single PV cell is simulated, and then a multiplier is used to calculate the output of a PV panel. In this way, the multiplier considers the number of series-connected PV cells in the panel. The multiplier changes the scale of the voltage-axis of the characteristic $I$ - $V$ (CurrentVoltage) curve, but not the slope of the curve [13], [15].

While PV cells are commonly connected in series inside PV panels, PV panels are connected in series-parallel connections to form PV arrays [15]. The focus in this work lies on commercial PV panels with series-connected PV cells. However, if not all PV cells are connected in series with each other inside a PV panel, the given topology has to be taken into account when analysing the impact of a defect in one PV cell on the output power of the PV panel.

\section{Background of the Research and Related Work}

Leppänen et al. developed synchronized thermography (ST) for the characterisation of thin films [16]-[18]. The method involved electrical heating of the conductive layer to measure its non-uniformity. At present, the closest technique comparable to ST is lock-in thermography (LIT). LIT has been applied to study defects of PV cells which are not encapsulated [19]-[23]. However, if PV cells are encapsulated by glass, it is difficult to measure them with the help of LIT, because temperature differences due to the modulated heating are too small and are diminished by the effect of the glass.

Other examples of comparable techniques are spatially resolved photoluminescence (PL) and electroluminescence (EL) imaging. For silicon-based PV cells, PL and EL imaging is used for quantitative measurements of parameters such as minority carrier lifetime, open-circuit voltage, diode saturation current, series and shunt resistance [24]-[30]. The principle of PL and EL imaging is based on the generalised Planck equation [31], [32]. In EL imaging, a current is driven through the PV cell, while in PL imaging, a uniform illumination source such as a laser or LEDs is used.

PL and EL imaging can be used to locate enhanced contact resistances and broken fingers inside a PV cell, for example [25]. Luminescence imaging can also be combined with illuminated lock-in thermography (ILIT) or dark lockin thermography (DLIT) in order to improve the obtained quantitative information about PV cell model parameters, for example, on the series and shunt resistance [27]-[30]. At present, the target of ST is not to obtain PV cell model parameters. Hence, the proposed method does not depend on a one-diode or two-diode model of a PV cell.

Furthermore, measurements with the help of ST are carried out when PV cells are connected with each other and are protected by glass. Previous research has demonstrated that ST can be used to characterise crystalline PV cells and panels on top of the conductive layer and through glass [10]. In contrast to ST, other techniques such as ILIT, DLIT, PL and EL imaging focus on an earlier fabrication stage of the PV panel in which measurements can be made without glass encapsulation. In summary, the goal of ST is

1) identifying the location of defects inside the PV panel through the protection glass,

2) estimating the geometric size of the defected area and,

3) estimating the impact of the defected area on the available output power of the PV panel.

Therefore, the proposed method has several advantages and disadvantages compared to other techniques. The complexity, costs and size of the ST measurement setup are significantly lower than for other techniques. Furthermore, ST does not require uniform illumination for the device under test (DUT) as do ILIT and PL imaging. Moreover, the power source does not need to be modulated as in DLIT, and operation at the maximum power point (MPP) as in PL imaging with current extraction is not required.

However, luminescence imaging enables a measurement time of about one second, while with ST the DUT needs to be heated up for $5 \mathrm{~s}$ without glass and for $45 \mathrm{~s}$ with glass. Vital information on the PV cell parameters such as the series and shunt resistance can also be obtained. In this way, a deeper understanding of the performance of the PV cell, in particular the cell efficiency, can be gained. In addition to area scanning, PL imaging can utilise line scanning, which allows contactless measurements while the DUT is moving [33].

\section{SYNChronized TherMography OF PV PANELS}

\section{A. Measurement Setup and Measurement Sample}

The basic measurement setup of ST is shown in Fig. 2. Here, an external power supply of $12 \mathrm{~V}$ and $1 \mathrm{~A}$ was applied to heat up the PV panels for $45 \mathrm{~s}$ in a dark, non-illuminated 
environment $\left(\lambda=0 \mathrm{~W} / \mathrm{m}^{2}\right)$ [9], [10]. These ambient circumstances are comparable to dark lock-in thermography (DLIT) [20]. After 45 s, IR-images were captured with a Flir b60 (image resolution: 180x180), an Optris PI 640 IR-camera (image resolution: 640x480), and a Flir ONE IR-camera (camera resolution: 160x120, image resolution: 640x480). Thus, synchronized means that the DUT is constantly heated for a specific amount of time before the IR-image is obtained.

One IR-camera was used at a time. Before each measurement was started, it was ensured that the PV panel under test has cooled down in order to achieve reproducibility of IRimage recording. At $t=0 \mathrm{~s}$, the power supply was switched on and the stopwatch started to record the measurement time. At $t=45 \mathrm{~s}$, the IR-image was obtained with the respective IRcamera. Experiments were repeated several times to estimate the uncertainty of the ST measurements.

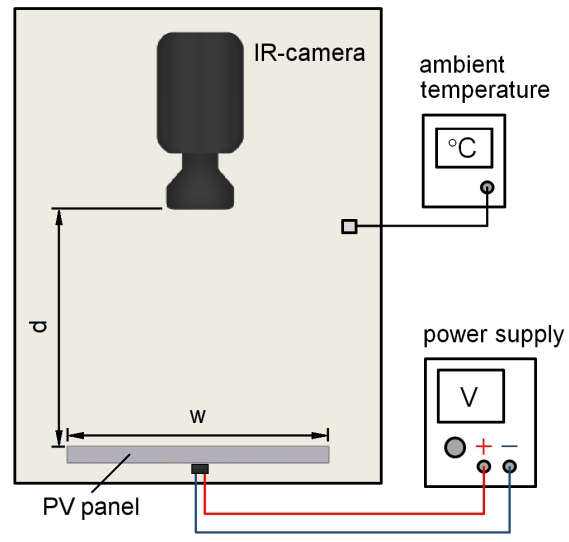

Fig. 2: Synchronized thermography measurement setup

The alignment of the measurement setup (see Fig. 2) was carried out in such a way that the IR-image covers the complete PV panel. Thus, the distance of the camera $(d)$ was adjusted to the width of the PV panel $(w)$. In this way, the use of the resolution of the IR-camera could be optimized. In IR-images with higher resolution, we expect to locate defects in the PV panels more precisely and to estimate the loss in output power more accurately.

It is worth noting that the Flir ONE costs 300 USD, while the costs of the Optris PI 640 are about 10,000 USD. As the Flir ONE provides IR-images in the same resolution (640x480) as the Optris PI 640, one of the aims of this research was to reduce the costs of the measurement setup for the given size of the PV panel. However, when obtaining a single IR-image of a larger PV panel, then the impact of the resolution of the IR-camera can be different than for a smaller PV panel.

The type of PV panel used in this research is the same as in previous research [3], [9], [10]. Fig. 3 shows the lowcost PV panel, to be more exact the model DSP-5P from the manufacturer [lux.pro] Corporation. The PV manufacturer provides tolerance limits of $\pm 3 \%$ for their PV panels on output performances at standard test conditions (STC) $(\lambda=$ $1000 \mathrm{~W} / \mathrm{m}^{2}$ and $T_{c}=25^{\circ} \mathrm{C}$ ). As seen in Fig. 3, the PV panel is made out of 18 polycrystalline PV cells which are connected in series with each other. Table I presents the available data from the PV manufacturer.

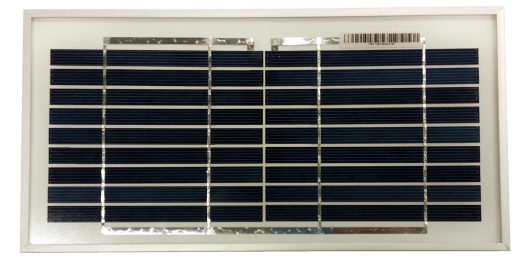

Fig. 3: PV panel DSP-5P from [lux.pro] Corporation

TABLE I: Available data of the [lux.pro] DSP-5P

\begin{tabular}{|c|c|}
\hline Parameter & Value \\
\hline $\mathrm{P}_{\mathrm{mpp}}[\mathrm{W}]$ & 5.00 \\
\hline $\mathrm{V}_{\mathrm{oc}}[\mathrm{V}]$ & 11.25 \\
\hline $\mathrm{I}_{\mathrm{sc}}[\mathrm{A}]$ & 0.81 \\
\hline $\mathrm{V}_{\mathrm{mpp}}[\mathrm{V}]$ & 9.00 \\
\hline $\mathrm{I}_{\mathrm{mpp}}[\mathrm{A}]$ & 0.56 \\
\hline length [mm] & 350 \\
\hline width [mm] & 174 \\
\hline height [mm] & 19 \\
\hline
\end{tabular}

AM1.5; $\lambda=1000 \mathrm{~W} / \mathrm{m}^{2} ; T_{c}=25{ }^{\circ} \mathrm{C}$; standard test conditions (STC)

\section{B. Obtaining and Analyzing IR-images}

We decided to use the same parameters (12 V supply voltage, 1 A current limit) for forward-biasing the encapsulated PV panels in order to obtain comparable results. To achieve this, we heated the PV panels for 45 seconds [3], [9], [10]. The temperature of an unheated reference sample was also measured with IR-imaging. By scaling the IR-image, we were able to demonstrate a difference between the temperature of the heated sample and unheated reference.

As mentioned above, the power supply was set to a supply voltage $\left(V_{\text {supply }}\right)$ of $12 \mathrm{~V}$ and a current limit $\left(I_{\text {limit }}\right)$ of $1 \mathrm{~A}$. Fig. 4 illustrates the applied current, in other words, the supply current $\left(I_{\text {supply }}\right)$, if a different supply voltage is chosen. As seen in Table I, the open-circuit voltage $\left(I_{o c}\right)$ of the PV panel is $11.25 \mathrm{~V}$. At a voltage lower than $12 \mathrm{~V}$, the current does not reach the maximum of $1 \mathrm{~A}$. At a voltage higher than $12 \mathrm{~V}$, the supply voltage remains at $12.2 \mathrm{~V}$.

Hence, as a guideline, the $V_{\text {supply }}$ should be set at a sufficiently large enough value (in respect to $V_{o c}$ of the PV panel) so that $I_{\text {limit }}$ obtainable from the power supply can be reached. If $V_{\text {supply }}$ is set to a lower voltage level, for example $11 \mathrm{~V}$, then the applied power $\left(P_{\text {supply }}\right)$ differs for each PV panel, as summarised in Table II. In order to maintain the same power and, thus, obtain comparable results, $V_{\text {supply }}=12 \mathrm{~V}$ is suitable to achieve $I_{\text {supply }}=I_{\text {limit }}=1 \mathrm{~A}$ and, therefore, $P_{\text {supply }}=12 \mathrm{~W}$.

TABLE II: Difference in supply current at a lower supply voltage

\begin{tabular}{|c|c|c|c|}
\hline & $V_{\text {supply }}$ & $I_{\text {supply }}$ & $P_{\text {supply }}$ \\
\hline PV panel 1 & $11.0 \mathrm{~V}$ & $0.41 \mathrm{~A}$ & $4.51 \mathrm{~W}$ \\
\hline PV panel 2 & $11.0 \mathrm{~V}$ & $0.45 \mathrm{~A}$ & $4.95 \mathrm{~W}$ \\
\hline PV panel 3 & $11.0 \mathrm{~V}$ & $0.36 \mathrm{~A}$ & $3.96 \mathrm{~W}$ \\
\hline PV panel 4 & $11.0 \mathrm{~V}$ & $0.46 \mathrm{~A}$ & $5.06 \mathrm{~W}$ \\
\hline PV panel 5 & $11.0 \mathrm{~V}$ & $0.40 \mathrm{~A}$ & $4.40 \mathrm{~W}$ \\
\hline PV panel 6 & $11.0 \mathrm{~V}$ & $0.43 \mathrm{~A}$ & $4.73 \mathrm{~W}$ \\
\hline
\end{tabular}

We measured six PV panels with both the Optris PI 640 IR-camera and the Flir ONE IR-camera and then calculated the temperature map of all samples. The temperature scale bar 


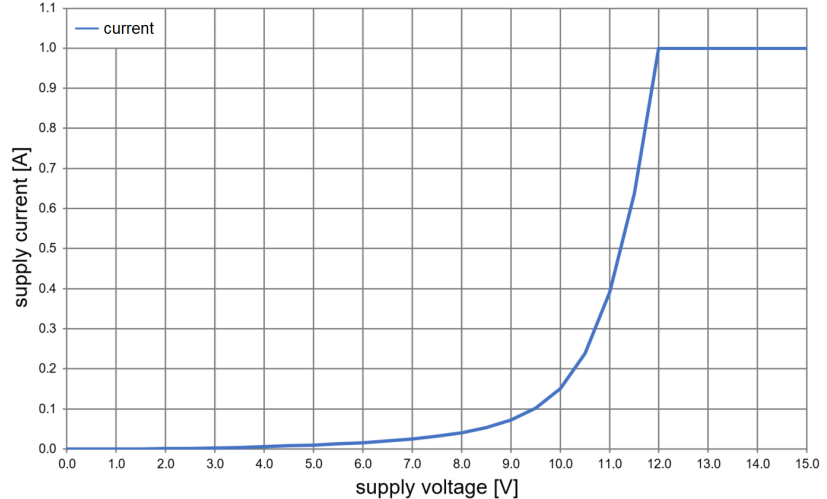

Fig. 4: Possible supply current vs. applied supply voltage

was formatted according to the obtained rises in temperature. Table III presents the maximum temperature increase in the particular PV panel obtained with the different IR-cameras. Due to a maximum temperature of $3.6{ }^{\circ} \mathrm{C}$ for both cameras, we decided to format the temperature scale from 0 to $4{ }^{\circ} \mathrm{C}$ above the ambient temperature.

TABLE III: Maximum temperature increase in PV panels obtained with different IR-cameras

\begin{tabular}{|c|c|c|}
\hline & Optris PI 640 & Flir ONE \\
\hline PV panel 1 & $3.5^{\circ} \mathrm{C}$ & $3.1^{\circ} \mathrm{C}$ \\
\hline PV panel 2 & $3.4^{\circ} \mathrm{C}$ & $3.2^{\circ} \mathrm{C}$ \\
\hline PV panel 3 & $3.0^{\circ} \mathrm{C}$ & $3.1^{\circ} \mathrm{C}$ \\
\hline PV panel 4 & $3.0^{\circ} \mathrm{C}$ & $2.9^{\circ} \mathrm{C}$ \\
\hline PV panel 5 & $3.6^{\circ} \mathrm{C}$ & $3.6{ }^{\circ} \mathrm{C}$ \\
\hline PV panel 6 & $3.5^{\circ} \mathrm{C}$ & $3.1{ }^{\circ} \mathrm{C}$ \\
\hline
\end{tabular}

Fig. 5 illustrates the obtained temperature differences in PV panel 1, while Fig. 6 show the differences in PV panel 3. For comparison, the IR-image obtained with the Flir b60 IR-camera is also shown [9], [10]. IR-imaging with the three different cameras was carried under the same conditions. In addition, the shapes of the PV cells and connecting wires are also illustrated in order to show approximately the position of the cells and wires in the IR-image. The higher temperature along the connection wires, which can be seen in Figs. 5 and 6, is normal. In previous research, we obtained the highest power at the maximum power point (MPP) $\left(P_{m p p}\right)$ from PV panel 3, while the lowest power at the MPP was observed in PV panel 2 [3], [9], [10]. Tables IV and V summarize the results of the electrical verification of the PV panels at different solar radiation levels and the calculated results in terms of loss in power at the MPP $\left(\Delta P_{m p p}\right)$.

Electrical verification of PV panels was carried out with the help of a similar setup as in [2] and [35] with the same measurement instruments (Voltcraft PL-110SM; Voltcraft DT300; Testboy TV 325) used in [36]. As in [2] and [35], the operating voltage of the PV panel under test was alternated from 0 to $V_{o c}$ while the output current $\left(I_{\text {out }}\right)$ was measured and recorded with the help of the National Instruments (NI) myDAQ in order to obtain the characteristic $I-V$ curve of the PV panels. In addition, the solar radiation level and PV cell temperature were obtained at the same time in order to ensure that the PV panels were tested under the same conditions. All

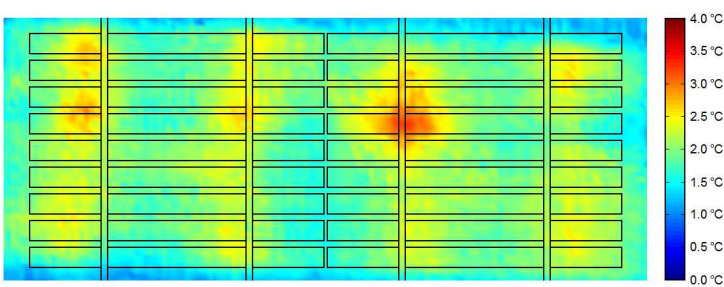

(a) IR-image obtained with the Flir b60 IR-camera

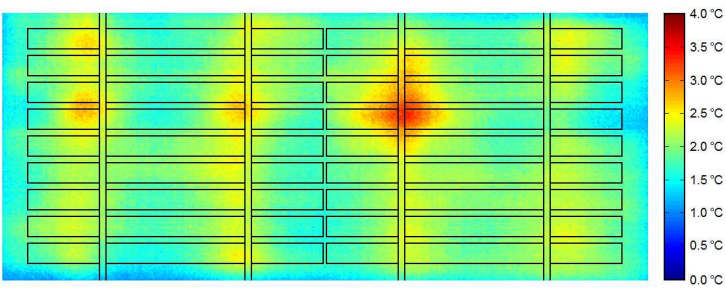

(b) IR-image obtained with the Optris PI 640 IR-camera

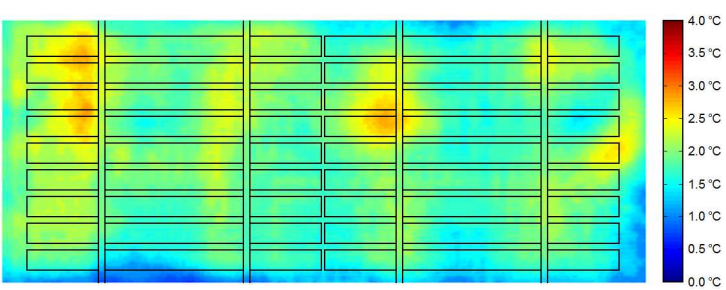

(c) IR-image obtained with the Flir ONE IR-camera

Fig. 5: Temperature differences in PV panel 1

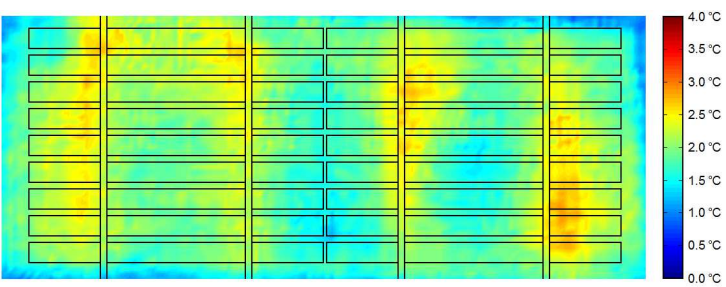

(a) IR-image obtained with the Flir b60 IR-camera

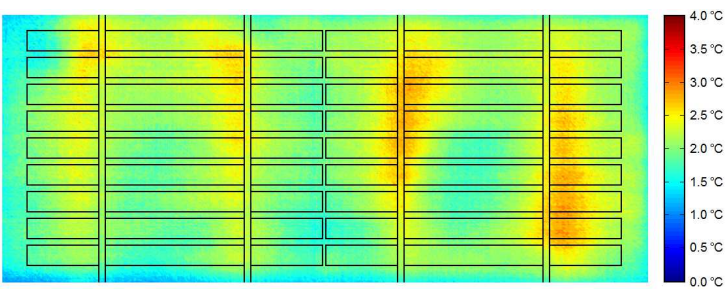

(b) IR-image obtained with the Optris PI 640 IR-camera

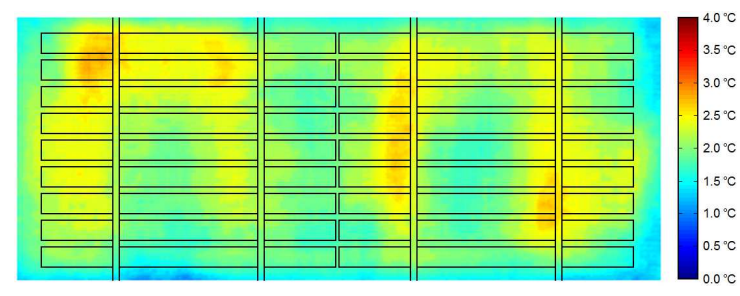

(c) IR-image obtained with the Flir ONE IR-camera

Fig. 6: Temperature differences in PV panel 3 
experiments were repeated for the calculation of the Type A uncertainty of the measurements. Then, the Type A uncertainty was combined with the Type B uncertainty which was obtained from the uncertainty of the measurement instruments within the experiments. The obtained relative uncertainties for $P_{m p p}$ did not exceed $3 \%$ as in [34] and [35].

The research set out to examine the relationship between the loss in output power measured in the experiments and the area with defects estimated with the help of ST. In order to allow comparison of results, a reference was chosen to calculate the difference in power at the MPP $\left(P_{m p p}\right)$ as a percentage $\left(\Delta P_{m p p}\right)$. PV panel 3 was selected as it provided the highest power, assuming that there were no defects in the PV panel. It is worth noting that the experimental results were not obtained at STC $\left(\lambda=1000 \mathrm{~W} / \mathrm{m}^{2}\right)$. Hence, we used a PV simulation model [1] in order to calculate the available power of the PV panels at STC. Tables IV and V summarise the difference in percentage $\left(\Delta P_{m p p}\right)$ between the $\mathrm{PV}$ panels at different solar radiation levels.

For panel 1, 2, 5, and 6, clear hot and cold spots can be observed in the middle of the cell string on the right-hand side of the PV panel [12]. Fig. 7 illustrates the area of defects. When PV cells have defects, the defect area can be physically and electrically disconnected from the rest of the PV cell, for example, due to the presence of a hairline crack [10]. Thus, no current runs through the defect area, and it does not heat up when the PV panel is forward biased. In fact, the current goes through the remaining area, marking it warmer than a healthy PV cell in the panel. As a result, we are able to indicate defects in PV panels based on hot and cold spots.

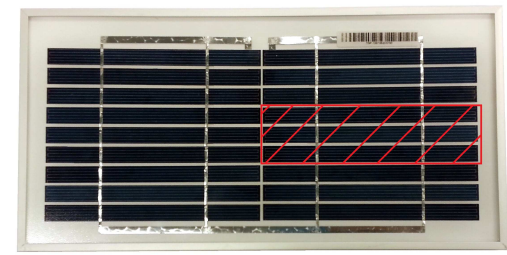

Fig. 7: Location of defects in the PV samples

\section{Estimating the Loss in Output Performance}

The resolution of the IR-image can have an impact on the estimation of the loss in output performance. The temperature map was evaluated in a similar way to [11]. In this research work, the focus lies on the performance of the weakest PV cell of the interconnection. In ST, the loss in output performance of the PV panel is calculated based on the estimated defect area of the perceived weakest PV cell of the PV panel, as described in Equation (1). In previous research, the temperature map of the whole PV panel from [lux.pro] Corporation was analyzed [9]. The average temperature ( $\left.T_{\text {average }}\right)$ was calculated at each horizontal segment of the weakest PV cell ( $\left.T_{\text {average,cell }}\right)$ and the reference PV cell ( $\left.T_{\text {average,reference }}\right)$ of the panel [11], obtained as follows:

$$
T_{\text {average }}=\frac{1}{n_{v}} \sum_{i=1}^{n_{v}} T_{i}
$$

where $n_{v}$ is the number of vertical line segments for one PV cell of the panel. It is worth noting that $n_{v}$ depends on the resolution of the IR-camera (i.e. the region of interest). At each location where the difference in the average temperature ( $\Delta T_{\text {average }}$ ) was lower (i.e. focus on cold spots) than the threshold temperature $\left(T_{\text {threshold }}\right)$, the horizontal line segment was assumed to be defect, calculated as follows:

$$
\begin{array}{r}
\Delta T_{\text {average }}=\frac{T_{\text {average,cell }}}{\frac{T_{\text {average, reference }}}{100}}-100 \\
\text { if } \Delta T_{\text {average }}<T_{\text {threshold }} \text { then } i=i+1
\end{array}
$$

$T_{\text {average, reference }}$ was taken from a healthy PV cell in the same string of PV cells in the same PV panel (outside the verified location of defects). $T_{\text {threshold }}$ was set to $-20 \%$. In other words, if the temperature in the weakest PV cell was more than $20 \%$ lower than the temperature in the reference PV cell, the horizontal line segment was assumed to be defect. The total number of defect segments was converted to a percentage of the total horizontal line segments $\left(N_{h}\right)$ for comparison.

Fig. 8 shows a comparison of the obtained results. The error bars, which are shown in Fig. 8 reflect the uncertainty of the electrical measurement and ST measurement, respectively. The uncertainties were calculated by estimating the uncertainty from experiments (Type A) and from instruments (Type B). The focus lies on the PV panels of the sample in which significant cold and hot spots were located.

$$
\Delta P_{m p p}=\frac{P_{m p p, \text { sample }}}{\frac{P_{m p p, \text { reference }}}{100}}-100
$$

In Fig. 8, the loss in output power in percentage $\left(\Delta P_{m p p}\right)$, shown in Table $\mathrm{V}\left(\lambda=500 \mathrm{~W} / \mathrm{m}^{2}\right)$, is compared with the estimated defect area based on the IR-images obtained with the help of synchronized thermography. Here, the difference in the estimated defect area is shown for the IR-images obtained with three cameras, the Flir b60, the Optris PI 640 and the Flir ONE IR-camera, respectively. As seen in Table VI and in Fig. 8, a strong agreement can be observed between the loss in output performance measured electrically and estimated with the help of ST and different IR-cameras.

\section{Impact of the Resolution on the Estimation}

The resolution of the IR-camera affects the total number of horizontal segments $\left(N_{h}\right)$ and, thus, the size of the fraction of one line segment $\left(n_{h}\right)$ which are used to estimate the size of the defect area as a percentage of the total area of the PV cell. In other words, a higher resolution of the IR-image enables a higher number of horizontal segments and, thus, a smaller $n_{h}$ and, hence, a more precise estimation of the defect area with the help of ST. Similarly, the resolution of the IR-camera affects the total number of vertical segments $\left(N_{v}\right)$ which are used to calculate the average temperature $\left(T_{\text {average }}\right)$. In Table VII, it can be seen how greater resolution increases the region of interest (ROI) and the number of horizontal segments. However, if needed, for example for larger PV panels, IRimages can be taken from parts of the PV panel (e.g. one string of cells) in order to increase the number of horizontal segments. 
TABLE IV: Experimental verification and computer simulation at different solar radiation levels

\begin{tabular}{|l|c|c|c|c|}
\hline & $\lambda=400 \mathrm{~W} / \mathrm{m}^{2}$ & $\lambda=500 \mathrm{~W} / \mathrm{m}^{2}$ & $\lambda=600 \mathrm{~W} / \mathrm{m}^{2}$ & $\lambda=1000 \mathrm{~W} / \mathrm{m}^{2}$ \\
\hline PV panel 1 & $\mathrm{P}_{\mathrm{mpp}}[\mathrm{W}]=1.60 \pm 0.044$ & $\mathrm{P}_{\mathrm{mpp}}[\mathrm{W}]=1.93 \pm 0.053$ & $\mathrm{P}_{\mathrm{mpp}}[\mathrm{W}]=2.26 \pm 0.062$ & $\mathrm{P}_{\mathrm{mpp}}[\mathrm{W}]=3.88 \pm 0.11$ \\
\hline PV panel 2 & $\mathrm{P}_{\mathrm{mpp}}[\mathrm{W}]=1.44 \pm 0.040$ & $\mathrm{P}_{\mathrm{mpp}}[\mathrm{W}]=1.74 \pm 0.048$ & $\mathrm{P}_{\mathrm{mpp}}[\mathrm{W}]=2.05 \pm 0.057$ & $\mathrm{P}_{\mathrm{mpp}}[\mathrm{W}]=3.49 \pm 0.10$ \\
\hline PV panel 3 & $\mathrm{P}_{\mathrm{mpp}}[\mathrm{W}]=1.92 \pm 0.053$ & $\mathrm{P}_{\mathrm{mpp}}[\mathrm{W}]=2.32 \pm 0.064$ & $\mathrm{P}_{\mathrm{mpp}}[\mathrm{W}]=2.72 \pm 0.075$ & $\mathrm{P}_{\mathrm{mpp}}[\mathrm{W}]=4.66 \pm 0.13$ \\
\hline PV panel 4 & $\mathrm{P}_{\mathrm{mpp}}[\mathrm{W}]=1.77 \pm 0.049$ & $\mathrm{P}_{\mathrm{mpp}}[\mathrm{W}]=2.14 \pm 0.059$ & $\mathrm{P}_{\mathrm{mpp}}[\mathrm{W}]=2.50 \pm 0.069$ & $\mathrm{P}_{\mathrm{mpp}}[\mathrm{W}]=4.29 \pm 0.12$ \\
\hline PV panel 5 & $\mathrm{P}_{\mathrm{mpp}}[\mathrm{W}]=1.70 \pm 0.046$ & $\mathrm{P}_{\mathrm{mpp}}[\mathrm{W}]=2.06 \pm 0.056$ & $\mathrm{P}_{\mathrm{mpp}}[\mathrm{W}]=2.42 \pm 0.066$ & $\mathrm{P}_{\mathrm{mpp}}[\mathrm{W}]=4.13 \pm 0.11$ \\
\hline PV panel 6 & $\mathrm{P}_{\mathrm{mpp}}[\mathrm{W}]=1.48 \pm 0.041$ & $\mathrm{P}_{\mathrm{mpp}}[\mathrm{W}]=1.78 \pm 0.049$ & $\mathrm{P}_{\mathrm{mpp}}[\mathrm{W}]=2.09 \pm 0.058$ & $\mathrm{P}_{\mathrm{mpp}}[\mathrm{W}]=3.58 \pm 0.10$ \\
\hline
\end{tabular}

$\mathrm{AM} 1.5 ; T_{c}=25^{\circ} \mathrm{C}$;

Measurements $\left(\lambda=400 \mathrm{~W} / \mathrm{m}^{2}, \lambda=500 \mathrm{~W} / \mathrm{m}^{2}, \lambda=600 \mathrm{~W} / \mathrm{m}^{2}\right)$ under outdoor environmental conditions PV simulation model for $\lambda=1000 \mathrm{~W} / \mathrm{m}^{2}$ (STC)

TABLE V: Obtained and calculated differences in terms of power in the MPP $\left(\Delta P_{m p p}\right)$

\begin{tabular}{|c|c|c|c|c|}
\hline & $\lambda=400 \mathrm{~W} / \mathrm{m}^{2}$ & $\lambda=500 \mathrm{~W} / \mathrm{m}^{2}$ & $\lambda=600 \mathrm{~W} / \mathrm{m}^{2}$ & $\lambda=1000 \mathrm{~W} / \mathrm{m}^{2}$ \\
\hline PV panel 1 & $\Delta \mathrm{P}_{\text {mpp }}[\%]=-17 \pm 2.3$ & $\Delta \mathrm{P}_{\text {mpp }}[\%]=-17 \pm 2.3$ & $\Delta \mathrm{P}_{\text {mpp }}[\%]=-17 \pm 2.3$ & $\Delta \mathrm{P}_{\text {mpp }}[\%]=-17 \pm 2.4$ \\
\hline PV panel 2 & $\Delta \mathrm{P}_{\mathrm{mpp}}[\%]=-25 \pm 2.1$ & $\Delta \mathrm{P}_{\mathrm{mpp}}[\%]=-25 \pm 2.1$ & $\Delta \mathrm{P}_{\mathrm{mpp}}[\%]=-25 \pm 2.1$ & $\Delta \mathrm{P}_{\mathrm{mpp}}[\%]=-25 \pm 2.2$ \\
\hline $\mathrm{PV}$ panel 4 & $\Delta \mathrm{P}_{\mathrm{mpp}}[\%]=-8 \pm 2.6$ & $\Delta \mathrm{P}_{\mathrm{mpp}}[\%]=-8 \pm 2.5$ & $\Delta \mathrm{P}_{\mathrm{mpp}}[\%]=-8 \pm 2.5$ & $\Delta \mathrm{P}_{\mathrm{mpp}}[\%]=-8 \pm 2.6$ \\
\hline PV panel 5 & $\Delta \mathrm{P}_{\mathrm{mpp}}[\%]=-11 \pm 2.4$ & $\Delta \mathrm{P}_{\mathrm{mpp}}[\%]=-11 \pm 2.4$ & $\Delta \mathrm{P}_{\mathrm{mpp}}[\%]=-11 \pm 2.4$ & $\Delta \mathrm{P}_{\mathrm{mpp}}[\%]=-11 \pm 2.4$ \\
\hline PV panel 6 & $\Delta \mathrm{P}_{\mathrm{mpp}}[\%]=-23 \pm 2.1$ & $\Delta \mathrm{P}_{\mathrm{mpp}}[\%]=-23 \pm 2.1$ & $\Delta \mathrm{P}_{\mathrm{mpp}}[\%]=-23 \pm 2.1$ & $\Delta \mathrm{P}_{\mathrm{mpp}}[\%]=-23 \pm 2.2$ \\
\hline
\end{tabular}

$\mathrm{AM} 1.5 ; T_{c}=25{ }^{\circ} \mathrm{C}$;

Measurements $\left(\lambda=400 \mathrm{~W} / \mathrm{m}^{2}, \lambda=500 \mathrm{~W} / \mathrm{m}^{2}, \lambda=600 \mathrm{~W} / \mathrm{m}^{2}\right)$ under outdoor environmental conditions PV simulation model for $\lambda=1000 \mathrm{~W} / \mathrm{m}^{2}$ (STC)

$\mathrm{PV}$ panel 3 as reference for the comparison

TABLE VI: Deviation between electrical verification and ST

\begin{tabular}{|c|c|c|c|c|}
\hline & PV panel 1 & PV panel 2 & PV panel 5 & PV panel 6 \\
\hline Optris PI 640 & $\delta[\%]=-0.5 \pm 3.4$ & $\delta[\%]=-1.1 \pm 3.2$ & $\delta[\%]=+0.3 \pm 3.5$ & $\delta[\%]=+0.2 \pm 3.2$ \\
\hline Flir ONE & $\delta[\%]=-0.7 \pm 3.5$ & $\delta[\%]=-2.4 \pm 3.3$ & $\delta[\%]=-2.3 \pm 3.6$ & $\delta[\%]=-3.6 \pm 3.3$ \\
\hline Flir b60 & $\delta[\%]=+2.7 \pm 3.7$ & $\delta[\%]=+0.7 \pm 3.5$ & $\delta[\%]=+1.0 \pm 3.8$ & $\delta[\%]=+3.0 \pm 3.5$ \\
\hline
\end{tabular}

Electrical measurements as reference

TABLE VII: Influence of the resolution on the number of horizontal segments (ST and TRT)

\begin{tabular}{|c|c|c|c|c|c|c|c|}
\hline & IR-image resolution & ROI with ST & $N_{h}$ with ST & $n_{h}[\%]$ with ST & ROI with TRT & $N_{h}$ with TRT & $n_{h}[\%]$ with TRT \\
\hline Flir ONE & $640 \times 480$ & $444 \times 182$ & 222 & 0.45 & $592 \times 246$ & 296 & 0.34 \\
\hline Optris PI 640 & $640 \times 480$ & $444 \times 182$ & 222 & 0.45 & & & \\
\hline Flir b60 & $180 \times 180$ & $166 \times 68$ & 83 & 1.20 & & & \\
\hline
\end{tabular}

Values for the PV panel model DSP-5P from [lux.pro] Corporation

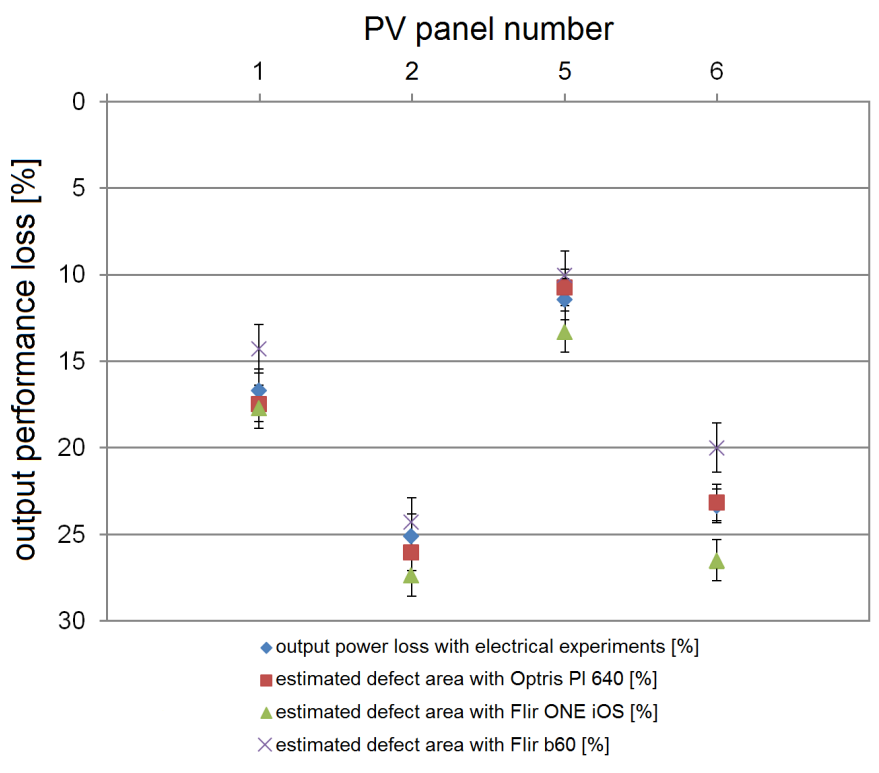

Fig. 8: Comparison of results

\section{Time-Resolved Thermography of PV Panels}

\section{A. Measurement Setup and Resolution Usage}

Fig. 9 shows the measurement setup of time-resolved thermography (TRT). As seen in Fig. 9, a Keysight E3631A power supply was used for forward-biasing the PV panel. The power supply was placed at a suitably large distance from the PV panel so that no interference in the recording occurred. A Flir ONE IR-camera was connected to a Samsung Galaxy S4 smartphone (GT-I9506). The measurement setup allowed us to use two thirds of the resolution of the IR-camera, as shown in Fig. 10.

We modified the measurement setup of ST used in previous research in [9]-[12] in different ways. Instead of taking IRimages manually after 45 seconds, we mirrored the screen of the smartphone via WiFi to a computer. On the computer, the screen of the smartphone was recorded at 30 frames per second. Monitoring the heating process of the PV panel on a continuous basis allowed us to remove the additional, unheated reference sample and the thermometer measuring the ambient temperature. In this way, the measurement setup is simplified. The reference of TRT is the IR-image obtained at $t=0$ $\mathrm{s}$, and temperature differences above the initial temperature 


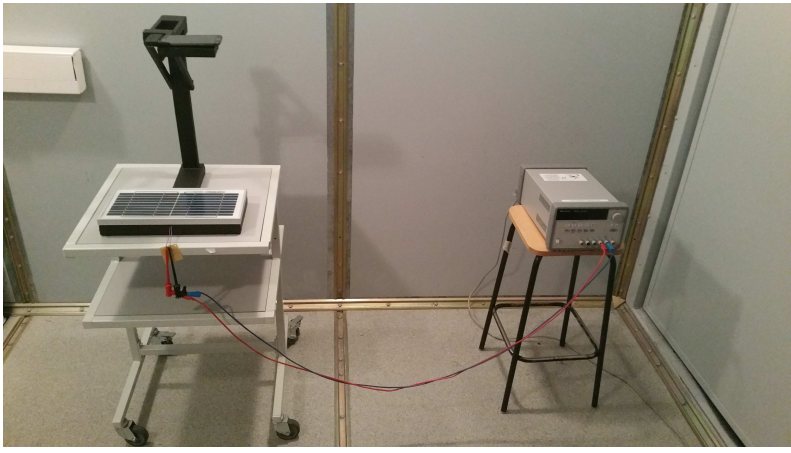

Fig. 9: Time-resolved thermography measurement setup

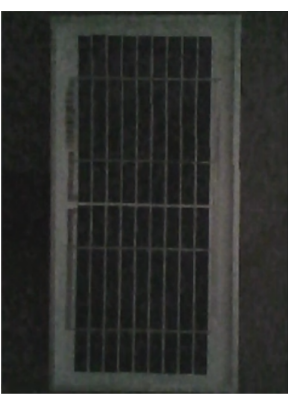

(a)

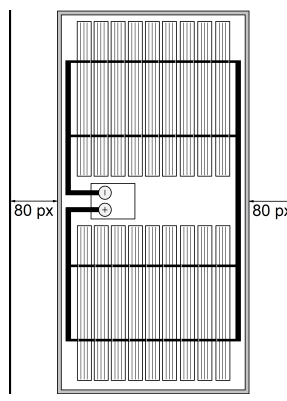

(b)
Fig. 10: (a) Recorded camera image (b) Resolution usage

were recorded. After 45 seconds of video-recording, 1350 IRimages were obtained. In summary, in comparison to ST, TRT allows

1) simplification of the measurement setup (e.g. references),

2) optimization of the use of the resolution of the IR-camera (for the DUT only, instead of measuring the DUT and a non-heated reference panel simultaneously, as seen in Table VII, and,

3) a reduction of the measurement time (from $45 \mathrm{~s}$ down to $30 \mathrm{~s})$.

\section{B. Experimental Results}

Fig. 11 shows the experimental results. The temperature scale is formatted according to the maximum temperature in the given time frame. As seen in the obtained IR-images, the location of the defect is visible already after $t=15 \mathrm{~s}$. The visibility of the location of a defect and, thus, the location of a hot and cold spot in the PV panel improves with the rise of the temperature differences in the PV panel. The temperature of the PV panel rises continuously, as shown in the example of the median and maximum temperature in Fig. 12. As indicated in Fig. 12, a heating time of $t=30 \mathrm{~s}$ is enough in order to achieve a reasonable agreement with electrical measurements, in other words, on average, a deviation between electrical verification and TRT measurements of $|\bar{\delta}|<2.0 \% \pm 3.5 \%$. Generally speaking, as seen in Fig. 12, an increase in the heating time results in a better agreement between the results of the two different measurement techniques. If the heating time is too low, for example $t=10 \mathrm{~s}$, non-defect areas are

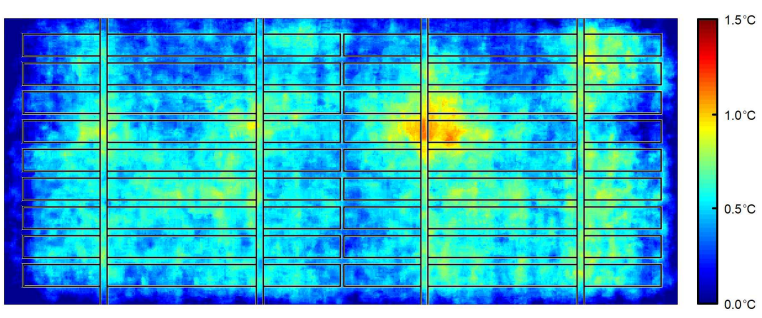

(a) $\mathrm{t}=15 \mathrm{~s}$; TRT with the Flir ONE IR-camera

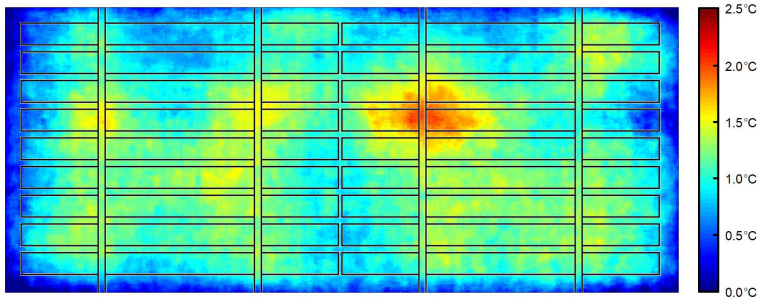

(b) t $=30 \mathrm{~s}$; TRT with the Flir ONE IR-camera

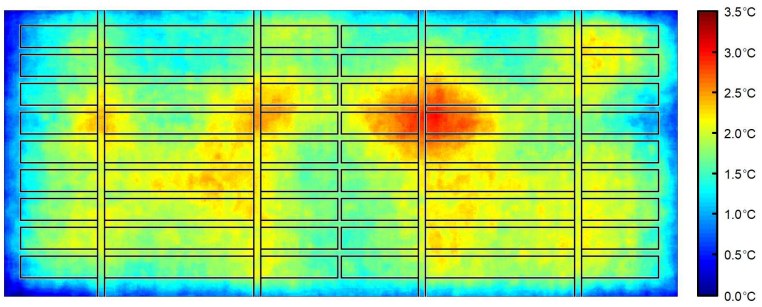

(c) $\mathrm{t}=45 \mathrm{~s}$; TRT with the Flir ONE IR-camera

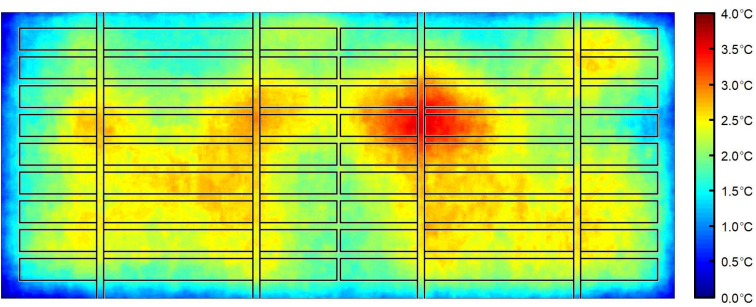

(d) $t=60 \mathrm{~s}$; TRT with the Flir ONE IR-camera

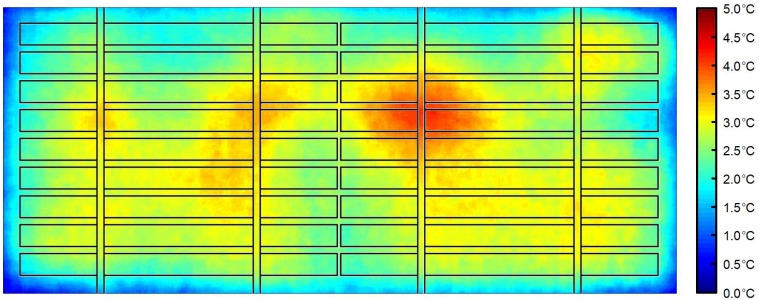

(e) $t=75 \mathrm{~s}$; TRT with the Flir ONE IR-camera

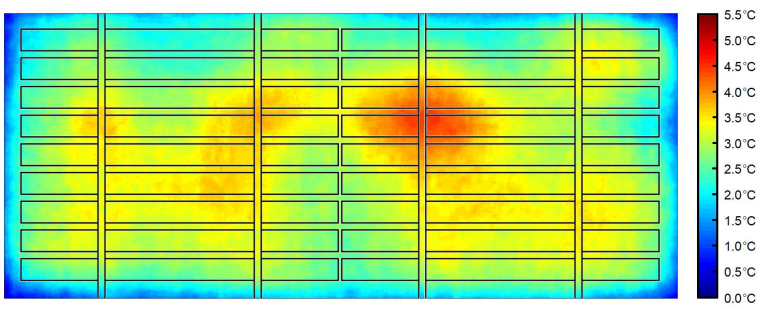

(f) $\mathrm{t}=90 \mathrm{~s}$; TRT with the Flir ONE IR-camera

Fig. 11: Temperature differences in PV panel 1 
falsely assumed to be defect and, as a result, a higher deviation is obtained.

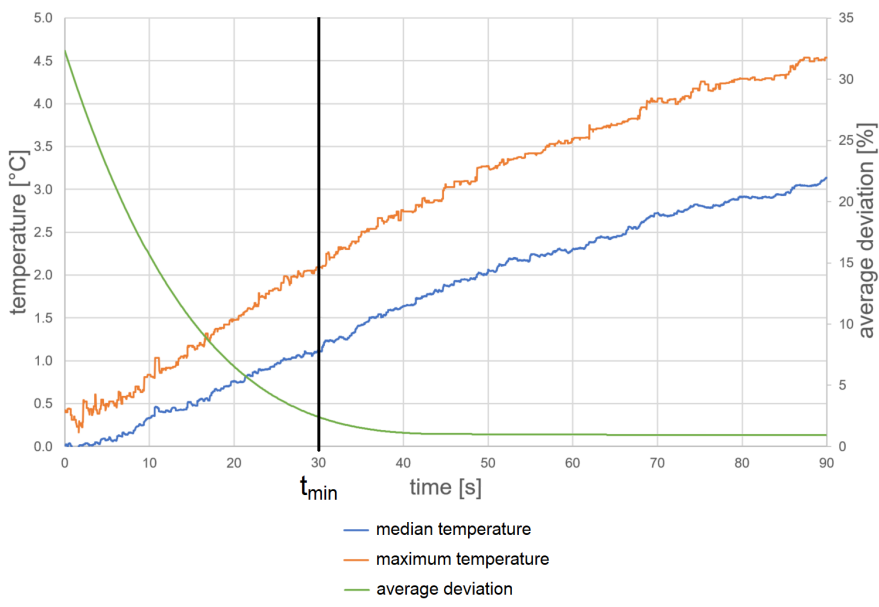

Fig. 12: Progression of temperatures and average deviation

\section{CONCLusion}

In this paper, we demonstrated that defects in PV panels can be located in IR-images obtained with the help of synchronized thermography (ST). The resolution of the IR-camera can have an impact on the amount of horizontal line segments $\left(N_{h}\right)$ which are used for estimating the loss in output power. A higher number of $N_{h}$ can result in a better agreement between the results of electrical verification and ST measurements. The location of defects was observed to be in the same area regardless of which IR-camera was used, indicating potential problems, for example in the manufacturing or packaging process.

Time-resolved thermography (TRT) can be used to simplify the measurement setup on one hand and increase the number of IR-images significantly on the other. Instead of taking a single IR-image at the end of the heating process, IR-images were recorded continuously. In this way, we were able to show that the heating process of PV panels takes place on a continuous basis. The location of the defect can be observed throughout the duration of the measurement. The visibility of the location of a defect, in other words the temperature differences in the IR-image, increases with the time the PV panel is biased forward.

\section{REFERENCES}

[1] M.G. Villalva, J.R. Gazoli, and E.R. Filho, "Comprehensive Approach to Modeling and Simulation of Photovoltaic Arrays", IEEE Transactions on Power Electronics, vol. 24, no. 5, pp. 1198-1208, 2009.

[2] L. Cristaldi, M. Faifer, M. Rossi, and F. Ponci, "A Simple Photovoltaic Panel Model: Characterization Procedure and Evaluation of the Role of Environmental Measurements", IEEE Transactions on Instrumentation and Measurement, vol. 61, no: 10, pp. 2632-2641, 2012.

[3] C. Schuss, B. Eichberger, and T. Rahkonen, "Measurement and Verification of Photovoltaic (PV) Simulation Models", Proceedings of the IEEE International Instrumentation and Measurement Technology Conference (I2MTC), pp. 188-193, 2013.

[4] R.N. Hall, "Silicon Photovoltaic Cells", Solid State Electronics, vol. 24 no: 7, pp. 595-616, 1981.

[5] M.A. Green, "General solar cell curve factors including the effects of ideality factor, temperature and series resistance", Solid State Electronics, vol. 20, no: 3, pp. 265-266, 1977.
[6] W. De Soto, S.A. Klein, and W.A. Beckman, "Improvement and validation of a model for photovoltaic array performance", Solar Energy, vol. 80, no: 1, pp. 78-88, 2006.

[7] M.G. Wanzeller, R.N.C. Alves, J.V. da Fonseca Neto, and W.A. dos Santos Fonseca, "Current Control Loop for Tracking of Maximum Power Point Supplied for Photovoltaic Array", IEEE Transactions on Instrumentation and Measurement, vol. 53, no: 4, pp. 1304-1310, 2004.

[8] F. Adamo, F. Attivissimo, A. Di Nisio, and M. Spadavecchia, "Characterization and Testing of a Tool for Photovoltaic Panel Modeling", IEEE Transactions on Instrumentation and Measurement, vol. 60, issue: 5, pp. 1613-1622, 2011.

[9] C. Schuss, K. Leppänen, Juha Saarela, Tapio Fabritius, B. Eichberger, and T. Rahkonen, "Detecting Defects in Photovoltaic Modules with the Help of Experimental Verification and Synchronized Thermography", Proceedings of the IEEE International Instrumentation and Measurement Technology Conference (I2MTC), pp. 97-102, 2015.

[10] C. Schuss, K. Remes, K. Leppänen, Juha Saarela, Tapio Fabritius, B. Eichberger, and T. Rahkonen, "Detecting Defects in Photovoltaic Cells and Panels and Evaluating the Impact on Output Performances", IEEE Transactions on Instrumentation and Measurement, vol. 65, no: 5, pp. 1108-1119, 2016.

[11] C. Schuss, K. Remes, K. Leppänen, Juha Saarela, Tapio Fabritius, B. Eichberger, and T. Rahkonen, "Estimating the Impact of Defects in Photovoltaic Cells and Panels", Proceedings of the IEEE International Instrumentation and Measurement Technology Conference (I2MTC), pp. 121-126, 2016.

[12] C. Schuss, K. Remes, K. Leppänen, Juha Saarela, Tapio Fabritius, B Eichberger, and T. Rahkonen, "Defect Localisation in Photovoltaic Panels with the Help of Synchronized Thermography", Proceedings of the IEEE International Instrumentation and Measurement Technology Conference (I2MTC), pp. 1270-1275, 2017.

[13] M.C. Di Piazza and M. Luna and G. Petrone, and G. Spagnuolo, "ModelBased Maximum Power Curves of Solar Photovoltaic Panels Under Partial Shading Conditions", IEEE Journal of Photovoltaics, vol. 7, no: 4, pp. 1009-1016, 2017.

[14] A. Xenophontos, and A.M. Bazzi, "Translation of the Single-Diode PV Model Parameters Identified by Using Explicit Formulas", IEEE Journal of Photovoltaics, vol. PP, no: 99, pp. 1-6, 2017.

[15] G. Petrone, C.A. Ramos-Paja, and G. Spagnuolo. Photovoltaic Sources Modeling. John Wiley \& Sons, 2017.

[16] K. Leppänen, J. Saarela, and T. Fabritius, "IR-imaging based system for detecting the defects of conductive materials", SPIE Optical Engineering + Applications, pp. 92050M-92050M, 2014.

[17] K. Leppänen, J. Saarela, R. Myllylä, and T. Fabritius, "Electrical heating synchronized with IR imaging to determine thin film defects", Optics Express, vol. 21, no: 26, pp. 32358-32370, 2013.

[18] K. Leppänen, J. Saarela, and T. Fabritius, "Synchronized thermography for multi-layer thin film characterization", SPIE Optical Engineering+ Applications, pp. 917705-917705, 2014.

[19] O. Breitenstein, "Nondestructive local analysis of current-voltage characteristics of solar cells by lock-in thermography", Solar Energy Materials and Solar Cells, vol. 95, no: 10, pp. 2933-2936, 2011.

[20] O. Breitenstein, "Local efficiency analysis of solar cells based on lockin thermography", Solar Energy Materials and Solar Cells, vol. 107, pp. 381-389, 2012

[21] K. Ramspeck, K. Bothe, D. Hinken, B. Fischer, J. Schmidt, and R. Brendel, "Recombination current and series resistance imaging of solar cells by combined luminescence and lock-in thermography", Applied Physics Letters, vol. 90, no: 15, pp. 153502, 2007.

[22] I. Geisemeyer, F. Fertig, W. Warta, S. Rein, and M.C. Schubert, "Prediction of silicon PV module temperature for hot spots and worst case partial shading situations using spatially resolved lock-in thermography", Solar Energy Materials and Solar Cells, vol. 120, pp. 259-269, 2014.

[23] T.-Y. Chung, C.-H. Wang, K.-J. Chang, S.-Y. Chen, H.-H. Hsieh, C.-P. Huang, and C.-H. A Cheng, "Evaluation of the spatial distribution of series and shunt resistance of a solar cell using dark lock-in thermography", Applied Physics Letters, vol. 115, no: 3, pp. 034901, 2014.

[24] T. Trupke, R.A. Bardos, M.C. Schubert, and W. Warta," "Photoluminescence imaging of silicon wafers", Applied Physics Letters, vol. 89, nr. 4, pp. 044107, 2006.

[25] T. Trupke, R.A. Bardos, M.D. Abbott, F.W. Chen, K. Fisher, and J.E. Cotter, "Luminescence imaging: an ideal characterization tool for silicon", $16^{\text {th }}$ Workshop on Crystalline Silicon Solar Cells and Modules: Materials and Processes, p. 50-57, 2006.

[26] Z. Hameiri, A. Mahboubi Soufiani, M.K. Juhl, L. Jiang, F. Huang, Y.-B. Cheng, H. Kampwerth, J.W. Weber, M.A. Green, and T. Trupke, "Photoluminescence and electroluminescence imaging of perovskite solar 
cells", Progress in Photovoltaics: Research and Applications, vol. 23, nr. 12, pp. 1697-1705, 2015.

[27] J. Oh, S. Dahal, B. Dauksher, S. Bowden, G. Tamizhmani, and P. Hacke, "A Novel Technique for Performing PID Susceptibility Screening during the Solar Cell Fabrication Process", $43^{\text {rd }}$ IEEE Photovoltaic Specialists Conference (PVSC), pp. 0907-0910, 2016.

[28] O. Breitenstein, F. Frühauf, J. Bauer, F. Schindler, and B. Michl, "Local solar cell efficiency analysis performed by injection-dependent PL imaging (ELBA) and voltage-dependent lock-in thermography (Local IV)", Energy Procedia, vol. 92, pp. 10-15, 2016.

[29] O. Breitenstein, and F. Frühauf, "Alternative luminescence image evaluation - Comparison with lock-in thermography", Solar Energy Materials and Solar Cells, 2017.

[30] F. Frühauf, J. Wong, J. Bauer, and O. Breitenstein, "Finite element simulation of inhomogeneous solar cells based on lock-in thermography and luminescence imaging", Solar Energy Materials and Solar Cells, vol. 162, pp. 103-113, 2017.

[31] P. Würfel, "The chemical potential of radiation", Journal of Physics C: Solid State Physics, vol. 15, nr. 18, pp. 3967, 1982.

[32] P. Würfel, S. Finkbeiner, and E. Daub, "Generalized Planck's radiation law for luminescence via indirect transitions", Applied Physics A: Materials Science \& Processing, vol. 60, nr. 1, pp. 67-70, 1995.

[33] T. Trupke, J. Nyhus, and J. Haunschild, "Luminescence imaging for inline characterisation in silicon photovoltaics", Physica Status Solidi (RRL)-Rapid Research Letters, vol. 5, nr. 4, pp. 131-137, 2011.

[34] Y. Hishikawa and T. Doi and M. Higa and K. Yamagoe, and H. Ohshima, "Precise Outdoor PV Module Performance Characterization Under Unstable Irradiance", IEEE Journal of Photovoltaics, vol. 6, nr. 5, pp. 1221-1227, 2016.

[35] A. Carullo, A. Castellana, A. Vallan, A. Ciocia, and F. Spertino, "Uncertainty issues in the experimental assessment of degradation rate of power ratings in photovoltaic modules", Measurement, vol. 111, pp. 432-440, 2017.

[36] C. Schuss, B. Eichberger, and T. Rahkonen, "Impact of Sampling Interval on the Accuracy of Estimating the Amount of Solar Energy", Proceedings of the IEEE International Instrumentation and Measurement Technology Conference (I2MTC), pp. 1355-1360, 2016.

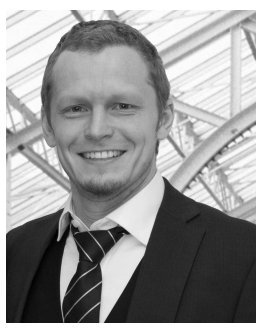

Christian Schuss (S'11-M'17) was born in Lienz, Austria, in 1983. He received the Dipl.-Ing. (Hons.) degree in information technology and the Dr.Techn. degree in automotive electronics from the Graz University of Technology, Graz, Austria, in 2010 and 2014, respectively, and the D.Sc. (Tech.) degree in electronics design from the University of Oulu, Oulu, Finland in 2017. He is currently a Research and Teaching Assistant with the Circuits and Systems (CAS) Research Unit, University of Oulu, Oulu, Finland.

His current research interests include renewable energy resources, energy harvesting and automotive electronics.

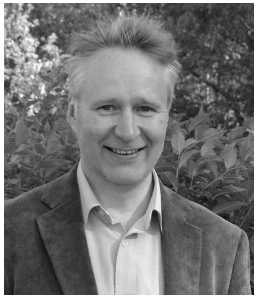

Kimmo Leppänen received the M.Sc. (Chem.) degree and D.Sc (Tech.) degree from University of Oulu, Finland, in 2010 and 2015, respectively.

He was a Researcher at the OPEM Research Unit. His research involved the characterization of covering materials, such as indium-tin oxide and $\operatorname{poly}(3,4-$ ethylenedioxy- thiophene):poly(styrenesulfonate), which are used in organic tandem solar cells. He has made a strong contribution to the development of synchronized thermography and other optical and electrical methods to characterize uniformity differences of conductive thin films. He is currently with MettlerToledo GmbH, Schwerzenbach, Switzerland, as a Technology and Application Manager for research instruments.

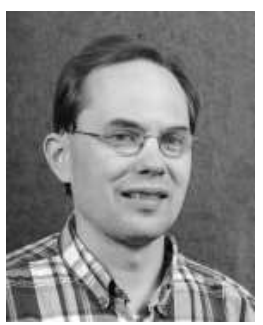

Juha Saarela received the M.Sc. (Tech.) and D.Sc. (Tech.) degrees in electrical engineering from the University of Oulu, Oulu, Finland, in 1998 and 2004, respectively.

$\mathrm{He}$ is currently a Lecturer at the University of Oulu, where he is also with the Printed Intelligence Research Group, Optoelectronics and Measurement Techniques Research Unit. His current research interests include photon migration in pulp and paper.

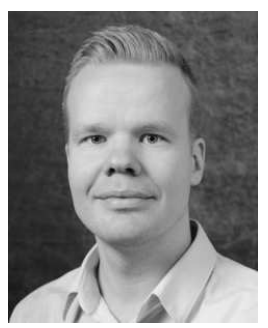

Tapio Fabritius received the M.S. and D.Sc. (Tech.) degrees in electrical engineering from the University of Oulu, Oulu, Finland, in 2003 and 2007, respectively. He was a Visiting Researcher with the Computational Optics Group, University of Tsukuba, Tsukuba, Japan, from 2006 to 2007. In 2009, he was conducting research with the Flexible Display Center, Tempe, AZ, USA. Since 2012, he has been the Research Director of PrintoCent, Oulu. He is currently the Head of the Printed Intelligence Group with the OPEM Research Unit, University of Oulu. He has co-authored over 60 papers. His current research interests include manufacturing and characterization of printed intelligence.

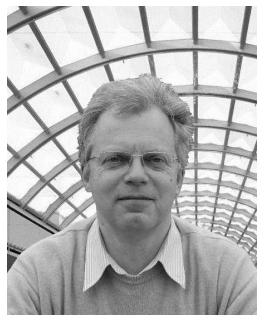

Bernd Eichberger was born in Bruck an der Mur, Austria, in 1961. He received the Diploma and Dr.Techn. (Hons.) degrees in electrical engineering from the Graz University of Technology, Graz, Austria, in 1990 and 1994, respectively.

$\mathrm{He}$ is currently a Professor with the Institute of Electronic Sensor Systems, Graz University of Technology. His current research interests include industrial and automotive electronic circuits and systems, new test and measurement principles, electronic engine control units, and fuel cell and lithiumion battery monitoring and diagnosis.

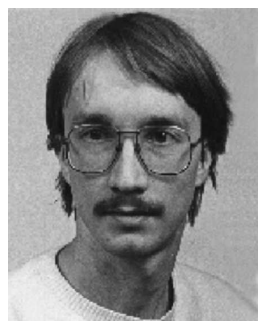

Timo Rahkonen (S'88-M'90) was born in Jyväskylä, Finland, in 1962. He received the Diploma Engineering, Licentiate, and D.Tech. degrees from the University of Oulu, Oulu, Finland, in 1986, 1991, and 1994, respectively.

$\mathrm{He}$ is currently a Professor of Circuit Theory and Circuit Design with the CAS Resaerch Unit and Infotech Oulu, University of Oulu, where he conducts research on linearization and error correction techniques for RF power amplifiers and $\mathrm{A} / \mathrm{D}$ and $\mathrm{D} / \mathrm{A}$ converters. 